\title{
CORRUPCIÓN PRIVADA: UN ESTUDIO DE LA AUSENCIA DE REGLAS DE DERECHO PRIVADO, DESDE EL CASO INTERBOLSA*
}

\section{PRIVATE CORRUPTION: A STUDY ON THE ABSENCE OF PRIVATE LAW RULES, SINCE THE INTERBOLSA CASE}

\author{
John Alberto Tito-Añamuro** \\ Fecha de recepción: 10 de mayo de 2015 \\ Fecha de aceptación: 24 de noviembre de 2015 \\ Disponible en línea: 30 de noviembre de 2015
}

\section{Para citar este artículo/To cite this article}

Tito-Añamuro, John Alberto, Corrupción privada: un estudio de la ausencia de reglas de derecho privado, desde el caso Interbolsa, 131 Vniversitas, 433-466 (2015). http://dx.doi.org/10.11144/Javeriana.vj131.cpea

doi:10.11144/Javeriana.vj131.cpea

* El presente trabajo es resultado de investigación del proyecto no financiado de la Universidad del Norte denominado "Propuesta para la creación de un Código de Consumo y Modernización del Derecho Privado Colombiano"

** Doctor en derecho, Universidad de Salamanca. Investigador permanente del Max-PlanckInstitut de Hamburgo, Alemania y profesor del Departamento de Derecho de la Universidad del Norte, Colombia. Contacto: jalbertotito@usal.es 


\section{RESUMEN}

Este trabajo estudia los actos de corrupción de Interbolsa y otras empresas, partiendo de la hipótesis de que para la neutralización de ilícitos, no solo es necesario el ángulo punitivo del derecho penal, sino además el de prevención y regulación de normas de derecho privado, en razón de que, desde un escenario prepunitivo, es posible tener un mayor control de los deberes de lealtad y confianza empresariales, necesarios para disipar el alto grado de fraude financiero y corrupción corporativa.

Palabras clave: corrupción privada; corrupción corporativa; empresas; Interbolsa; fraude financiero 


\section{ABSTRACT}

This work studies the acts of corruption of Interbolsa and other companies, based on the hypothesis that to counteract illegal acts it is not only necessary the punitive angle of private law, but that of prevention and regulation of private law rules. This is based on the idea that, from a pre-punitive angle, it is possible to have a greater control over the corporate loyalty and trust duties necessary to remove the high degree of financial fraud and corporate corruption.

Keywords: private corruption; corporate corruption; companies; Interbolsa; financial fraud

\section{SUMARIO}

Introducción.- I. El caso Interbolsa como premisa de partida.- $A$. Crónica sucinta de los hechos.- B. La puesta en evidencia de la insuficiencia de la norma y los ámbitos de responsabilidad.- II. UsO DE CATEGORÍAS DE DERECHO PRIVAdo.- A. Sociedades encubiertas.- 1. Sociedades Off-Shore.- 2. Sociedades de baja intensidad.- 3. Sociedades fiduciarias auténticas.- 4. Sociedades fiduciarias de testaferros o puramente instrumentales.- 5. Sociedades fantasma.- B. Operaciones de reporto.- III. MATER IALES PARA LA SOLUCIÓN DE LA CORRUPCIÓN DESDE LA ÓPTICA DEL DERECHO COMPARADO.BiBLIOGRAFÍA. 


\section{INTRODUCCIÓN}

El 94\% de los empresarios cree que se ofrecen sobornos en el entorno de negocios, mientras que $62 \%$ considera que si no se pagan sobornos, se pierden negocios. Dichos resultados son consistentes con los del Índice Global de Competitividad del WEF [World Economic Forum], donde Colombia se ubicó en 2014 en el puesto 105 entre 144 países en la variable correspondiente a pagos irregulares y sobornos ${ }^{l}$.

Con estos datos estadísticos y los recientes escándalos financieros de Interbolsa y Ecopetrol, resulta evidente que la corrupción yace no solo en el sector público, sino también en el privado. De ello, lo sorprendente es que los índices de corrupción privada reflejan consecuencias tanto o más graves que las del ámbito público ${ }^{2}$. Así, la corrupción pública o privada no supone nada nuevo bajo la lupa del contexto social, dado que siempre ha estado enhebrada en conductas públicas y privadas ${ }^{3}$. Si se quiere ser más específico en

1 Consejo Privado de Competitividad, CPC, Informe Nacional de Competitividad 2014-2015: Corrupción (Consejo Privado de Competitividad, CPC, Bogotá, 2014). Disponible en: http:// www.compite.com.co/site/informe-nacional-de-competitividad-2014-2015/, http://www.compite.com.co/site/wp-content/uploads/2014/11/CPC_INC-2014-2015-Corrupcion.pdf

2 Miguel Gómez-Martínez, Corrupción privada, Portafolio, 1 (3 de abril de 2012). Disponible en: http://www.portafolio.co/columnistas/corrupcion-privada. A este respecto, según el autor, Jaime Raúl Ardila-Barrera, auditor general de la República, dijo, "que la corrupción en el sector público puede estar alrededor de los cuatro billones de pesos, y que no hay estimativos de cuánto cuesta la del sector privado, que debe ser de enormes proporciones". Esto corrobora la magnitud negativa y análoga de los efectos de la corrupción, partiendo de ambos extremos, esto es, la pública y la privada.

3 Curiosamente, se decía, según Frédéric Boehm, que un instrumento para reducir la corrupción pública era la privatización. No obstante, otros como Susan Rose-Ackerman y Joseph Stiglitz, citados por Boehm, señalaban que la privatización y la regulación podían crear oportunidades para la corrupción y la presión de los grupos de interés. Con base en estas cuestiones, el autor desarrolla un interesante trabajo desde un punto de análisis no tradicional, esto es, el enfoque neoinstitucional, es decir, desde la lógica de los instrumentos de medición de la economía llevada a las normas y a las decisiones políticas. En este contexto, examina cómo actividades empresariales como las desintegraciones verticales y la subasta del monopolio por medio de concesiones, generan un jugoso escenario de corrupción. Algo que debe tomarse en cuenta, por ejemplo, para el supuesto de la corrupción de Interbolsa y Ecopetrol, entre otras empresas, que frente a los vacíos regulativos sus actividades hallan un engarce eficaz para la deslealtad y el fraude. Lógicamente, esas desintegraciones y subastas son autorizadas por la ley, de modo que se podría pensar que la regulación genera corrupción. El autor intenta soslayar esto precisamente con el argumento de la economía, es decir, que para esta ciencia y sus instrumentos de medición una regla jurídica solo genera incentivos, que deben tomarse en cuenta para delimitar los contornos de la corrupción. FréDÉRIC BoEHM, Corrupción y captura en la regulación de los servicios públicos, 7 Revista de Economía Institucional, 13, 245-263, 247 (2005). Disponible en: http://www.cdh.uchile.cl/media/publicaciones/pdf/5/283.pdf 
cuanto a esta última, en el inconsciente colectivo reposa la idea de que es inofensiva, casi admitida de ordinario por los destinatarios de la norma, incluso necesaria, desde un ángulo economicista de las cosas ${ }^{4}$. Con todo, resulta poco creíble que los sobornos corporativos, a veces de poca cuantía, resulten más dañinos que aquellos prototípicos y escandalosos supuestos de corrupción especialmente política. Ello no está tan alejado de la realidad, si se ven las cosas desde un punto de vista tradicional ${ }^{5}$.

Sin embargo, la cosas han cambiado, y mucho. Lo primero que se ha de adelantar en relación con esto es que el avance de la ciencia y tecnología y la liberalización de los mercados han modificado no solo las formas de contratación, sino también el comportamiento de los empresarios a la hora de alcanzar los jugosos rendimientos que ofrece un mercado global. A modo de ejemplo están los desastrosos casos Parmalat y Enron, cuyos empresarios llevaron al colapso, no solo a sus empresas, sino a sus sistemas financieros y bursátiles ${ }^{6}$.

Frente a ello, como ha sido de ordinario en materia de producción normativa, han sido los países industrializados, concretamente Estados Unidos y los de la Unión Europea, los que han puesto cartas en el asunto, situando en el escenario del derecho una serie de directrices y normas para disipar los efectos nocivos de esas malas

4 Sebastián Oleas, Corrupción, Coyuntura, 1-8 (2015). En este sentido, desde la economía, se han presentado argumentos a favor de la necesidad de la corruptela leve, que sería útil para la dinámica de las actividades de mercado, claro está, a condición de que esas actividades se enfrenten a regulaciones legales inútiles o entorpecedoras del mercado. Como señala el autor, estos economistas han presentado argumentos a favor de la corrupción como mejoradora de la eficiencia en países con rampante corrupción, incluso impulsa el crecimiento de aquellos Estados.

5 En un interesante artículo, el profesor Andrés Botero-Bernal saca a la luz la lucha de poderes o tensión, como lo llama él, entre el poder jurídico y el poder político: el primero, que marca o delinea con su poder lo que la corrupción es, cómo opera y dónde se presenta la corrupción, yo diría además que de manera particular delimita la conducta del destinario de la norma en qué es y no es corrupción, por medio de normas punitivas del derecho penal; y el segundo, esto es el poder político, abre frentes no regulados o más bien se desenvuelve con libertad en esos frentes no regulados, y en los ya regulados busca la evasión de la norma. En esta tensión, razona el autor que "cuando el sistema político invade el mundo jurídico atiborrándolo de normas anticorrupción, pero de manera que ellas simplemente rijan como un símbolo funcional para el propio sistema (corrupto), se logra poner el derecho al servicio de lo que pretende controlarse". En suma, en materia de corrupción solo hay eficacia simbólica, es decir, no hay una eficacia real. ANDRÉs BOTERO-BERNAL, La corrupción: tensión entre lo político y lo jurídico, 3 Opinión Jurídica, 6, 37-58, 40 (2004). Disponible en: http://revistas.udem.edu.co/index.php/ opinion/article/view/1314/1295

6 Fernando Carbajo, Corrupción en el sector privado (I): la corrupción privada y el derecho privado patrimonial, 10 Iustitia, 281-342 (2012). Disponible en: http://www.ustabuca.edu.co/ gpresenzia/vista/tpl/ustabmanga/revista-iustitia.html 
prácticas corporativas, con la particularidad de que a la hora de legislar se ha tenido especial atención no solo en la protección de intereses públicos, como ha sido de ordinario en la tipificación de ilícitos, sino además de intereses privados de accionistas, inversores, trabajadores, acreedores, consumidores, entre otros, y de los del sistema financiero y económico en conjunto?

Gracias a ello, se ha puesto en vigencia una serie de políticas y normas jurídicas de lucha contra la corrupción privada, siendo una de las más relevantes en el ámbito transnacional la Convención de Naciones Unidas contra la Corrupción ${ }^{8}$, que constituye, si se miran bien las cosas, el primer instrumento global para prevenir y luchar contra la corrupción sobre la base de un amplio consenso internacional'.

Si bien en el contexto latinoamericano, y concretamente en el colombiano, los casos de corrupción privada son análogos a los de la Unión Europea, las políticas públicas y las normas jurídicas no son como las de la Unión Europea. No pueden serlo obviamente, pero cuando menos se podrían haber recogido las líneas y contenidos jurídicos en lo fundamental para neutralizar esas prácticas nocivas. Ello se ha visto, en derecho colombiano, particularmente, desde el sistema penal. En efecto, en 2011 se puso en vigor el Estatuto Anticorrupción con la Ley 1474 de mecanismos de prevención, investigación y sanción de actos de corrupción, la cual recoge una serie de sanciones para inconductas de trabajadores, accionistas, socios, revisores fiscales y directivos de sociedades de naturaleza

7 Fernando Carbajo, Corrupción en el sector privado (I): la corrupción privada y el derecho privado patrimonial, 10 Iustitia, 281-342 (2012). Disponible en: http://www.ustabuca.edu.co/ gpresenzia/vista/tpl/ustabmanga/revista-iustitia.html

8 Organización de Naciones Unidas, Convención de Naciones Unidas contra la Corrupción, Resolución 58/4 de la Asamblea General de Naciones Unidas, 31 de octubre de 2003, en vigor desde 2005. Disponible en: http://www.unodc.org/pdf/corruption/publications_unodc _convention-s.pdf

9 Un interesante trabajo en relación con la medición de impacto de las reglamentaciones internacionales y nacionales en materia de corrupción es el de Ana González y Frédéric Boehm, en el cual se saca a la luz distintos índices de percepción de la corrupción a escala global y nacional, entre los que destacan Transparencia Internacional y los indicadores de gobernabilidad del Banco Mundial. Arguyendo los autores que medir la gobernabilidad y específicamente la corrupción se han convertido en una necesidad, dado que es indispensable para convencer al sector privado de la necesidad de luchar contra la corrupción y saber qué impacto logran las reformas. Ana Carolina González-Espinosa \& Frédéric Boenm, Medir la corrupción: de la generación de conciencia a los peligros de la mala interpretación, 11 Revista Ópera, 259-277, 262 (2013). Disponible en: http://revistas.uexternado.edu.co/index.php/opera/ article/view/3573/3609 
privada. En tal escenario de regulación, los responsables purgarían penas de 6 a 10 años de prisión, por ejemplo, para el ilícito de corrupción privada y, entre otros, de 4 a 8 años para el delito de administración desleal ${ }^{10}$. Pero nada se ha dicho en relación con la modificación o creación de normas de derecho privado, como sí se han hecho, ya se dijo, en sistemas jurídicos comparados.

No es extraño por ello que en derecho colombiano ante la insuficiencia, no solo de la norma, sino de su aplicación, se haya puesto en libertad a uno de los principales responsables del escándalo de Interbolsa, el italiano Alessandro Corridori. Y a pesar de que la Fiscalía haya reaccionado con la revisión de esa decisión judicial ${ }^{11}$, nada ha modificado el inconsciente colectivo:

La justicia, como los hechos lo demuestran, suele ser más benévola con la corrupción privada que con la del sector público, a pesar de ir amarradas en un matrimonio indisoluble ${ }^{22}$.

Este cúmulo de cosas nos lleva a la lógica de que los ilícitos no pueden afrontarse solo desde el ángulo punitivo del derecho penal, se precisan además estrategias de prevención, no solo de sanción, sino de regulación de normas de derecho privado. No puede perderse de vista que los actos de empresa y actividades de empresarios, trabajadores, administradores, gestores y comisionistas, entre otros, empiezan en terreno privado, por lo que la causalización de los deberes de lealtad y confianza privadas debería partir desde este escenario prepunitivo.

Por ello, en este trabajo, se hará una exploración de las normas que en materia de derecho privado patrimonial sean congruentes con la resolución de casos de corrupción privada, bajo un examen y análisis de categorías jurídicas de derecho comparado.

10 Ley 1474 de 2011, por la cual se dictan normas orientadas a fortalecer los mecanismos de prevención, investigación y sanción de actos de corrupción y la efectividad del control de la gestión pública, 48.128 Diario Oficial, 12 de julio de 2011. Disponible en: http://www.secretaria senado.gov.co/senado/basedoc/ley_1474_2011.html

11 María Fernanda Zuluaga, Corridori queda libre y jueza defiende decisión. Funcionaria que ordenó libertad del cerebro del descalabro de Interbolsa critica a la Fiscalía, El Tiempo (2 de julio de 2015). En un comunicado, la Fiscalía alegó que le llama la atención lo ocurrido y no está de acuerdo con los argumentos esbozados por la jueza, que entrará a revisar la decisión proferida y adoptará las decisiones de fondo que considere pertinentes en el trámite de este proceso.

12 María Elvira Bonilla, ¿Y la corrupción privada?, El País (2 de mayo de 2013). Disponible en: $\mathrm{http} / / / \mathrm{www}$.elpais.com.co/elpais/opinion/columna/maria-elvira-bonilla/y-corrupcion-privada 


\section{EL CASO INTERBOLSA COMO PREMISA DE PARTIDA}

El 24 de marzo de 2009, Rodrigo Jaramillo Correa sintió que tocaba el cielo con las manos. Logró la máxima aspiración de un corredor de bolsa: fue invitado a hacer sonar la campana que da inicio a las operaciones en la Bolsa de Valores de Nueva York ${ }^{13}$.

En aquel tiempo, nada avizoraba que tras esa cortina de protocolos finísimos de la élite bursátil más importante del planeta, se urdían maquinaciones insidiosas de uno de los mayores desastres financieros del país: el fraude de Interbolsa. En un abrir y cerrar de ojos, la corredora de bolsa colombiana más relevante del mercado bursátil llegó a ser la más señalada por actos de corrupción y fraude, y no solo a empresas, sino a miles de accionistas, entre ellos ciudadanos comunes y corrientes, que siguiendo la línea de democratización de la bolsa invirtieron confiados en que sus dineros iban a ser correctamente administrados.

Nada más alejado de la realidad. Ello en razón de que la comisionista en su pico más alto de inversiones y de éxito incumplió obligaciones de pago, fruto de los famosos "repo" (préstamo con garantía prendaria de acciones), colocados en Fabricato, una de las empresas usadas para simular liquidez. Como consecuencia de esto, Interbolsa cayó en cascada hasta el colapso, que se inició con la negativa del BBVA de seguir prestándole dinero. Dado que ni solvencia ni crédito estaban garantizados, a raíz de esos incumplimientos, el 2 de noviembre de 2012, la Superintendencia Financiera la intervino, con el fin de proteger a los miles de inversionistas de la comisión de una serie de delitos financieros, los cuales tras la renuncia (al día siguiente) de los principales directivos, tenían no solo sospechas, sino que corroboraban la urgencia de la intervención gubernamental ${ }^{14}$.

13 Los 5 momentos de Interbolsa, Revista Dinero (16 de noviembre de 2014). Disponible en: http:// www.dinero.com/pais/articulo/momentos-mas-importantes-interbolsa/203272

14 La Superintendencia Financiera tomó posesión formal de los activos de Interbolsa, mediante Resolución 1795 de 2012, por la cual según se señala en el documento se adopta la medida de toma de posesión inmediata de los bienes, haberes y negocios de la sociedad comisionista de bolsa Interbolsa S.A., acto administrativo regulado en el artículo 114, numeral 1, letra a del Estatuto Orgánico del Sistema Financiero de Colombia. Superintendencia Financiera, Resolución 1795 de 2012, por medio de la cual se adopta la medida de toma posesión inmediata 


\section{A. Crónica sucinta de los hechos}

\section{En Medellín, en 1990, nació al mercado Interbolsa como sociedad anónima con fines de inversión especialmente bursátil. Fundada por Rodrigo Jaramillo-Correa y otros socios, a ellos se unió en 1997 Juan Carlos Ortiz-Zárrate, quien le dio a la firma una visibilidad y un éxito que no había tenido antes. Entre 1998 y 2003 (fecha en la que Ortiz dejó la sociedad), el patrimonio de Interbolsa alcanzó $\$ 54.672$ millones $^{15}$. Este balance fue fantástico, si se tiene en cuenta que en 1998 su haber rondaba solo $\$ 3.000$ millones $^{16}$. Este crecimiento obedeció, según la calificadora de riesgo BRC Standard \& Poor's, entre otras cosas, al mecanismo de "posición propia"'}

de los bienes, haberes y negocios de la sociedad comisionista de bolsa INTERBOLSA S.A. Disponible en: www.portafolio.co/sites/portafolio.co/files/r1795_12.doc. Decreto 663 de 1993, por medio del cual se actualiza el Estatuto Orgánico del Sistema Financiero y se modifica su titulación y numeración, 40.820 Diario Oficial, 5 de abril de 1993. Disponible en: http:// www.secretariasenado.gov.co/senado/basedoc/estatuto_organico_sistema_financiero.html

15 BRC Investor Services, Revisión anual Interbolsa S. A., Sociedad Comisionista de Bolsa (2004). Disponible en: http://brc.com.co/archivos/RAInterbolsa-Dic04.pdf

16 Norbey Quevedo, Interbolsa: la debacle anunciada. La liquidación de la sociedad, El Espectador (11 de noviembre de 2012). Disponible en: http://www.elespectador.com/noticias/investigacion/ interbolsa-debacle-anunciada-articulo-386382

17 BRC Investor Services, Revisión anual Interbolsa S. A., Sociedad Comisionista de Bolsa (2004). Disponible en: http://brc.com.co/archivos/RAInterbolsa-Dic04.pdf

18 Según el informe Revisión anual, de BRC, la mayor parte de los ingresos de la compañía proviene de la posición propia, principal línea de negocio, desde hace varios años. Así, Interbolsa negocia principalmente títulos de deuda pública interna (TES, Títulos de Tesorería) y externa (en especial, Yankees) y divisas como el euro y el dólar. La calificadora de riesgo señala que el fortalecimiento patrimonial de la entidad le ha permitido posicionarse en el mercado de deuda pública y mantenerse dentro del programa Creadores de Mercado. Por otra parte, y consciente del mayor riesgo asumido por la elevada concentración de sus ingresos en esta línea de negocio, la compañía, desde hace varios años, ha venido fortaleciendo sus políticas y herramientas para el control de los diferentes riesgos (crédito, mercado y operacional) asumidos en el desarrollo de su operación.

No debe llamar la atención que un documento análogo a este - un informe completamente favorable - le sirvió a la comisionista para posicionarse en el piso más alto del mercado bursátil. En supuestos de desviación de informes, como podría ser este, y como han sido los de la época del colapso financiero, tal documento sirvió para construir los naipes del castillo, que gradualmente se fue erigiendo. En este informe anual, la calificadora señala que "el mantenimiento de la calificación se fundamenta en el favorable desempeño financiero de la compañía y su continuo crecimiento patrimonial, que le ha permitido posicionarse como uno de los más importantes actores del mercado de deuda pública, en el cual además participa como creador de mercado. Asimismo, se fundamenta en el fortalecimiento de la estructura de control interno, la parametrización de los procedimientos y de los manuales correspondientes a la medición de riesgo, la prevención y control de lavado de activos y el riesgo operacional, entre otros, y los adelantos en materia de gobierno corporativo que ha realizado la compañía durante el último año". Este informe inicia y concluye fundamentando la calificación de AA (doble A), que indica que la administración de riesgo, la capacidad operativa, la estructura financiera, la eficiencia y la capacidad gerencial de las instituciones calificadas en esta categoría, son muy buenas. 
y no de terceros ${ }^{19}$. Una muestra de ello fue la instrumentalización de inversiones por medio de los famosos 'repo', es decir, el préstamo de dinero a corto plazo (a veces, un día) con garantía de dejar en prenda las mismas acciones u otras análogas, la cual se explica de manera dinámica más adelante ${ }^{20}$.

En 2003, salieron a la luz las primeras grietas de la comisionista. Por ese tiempo, la Superintendencia de Valores la sancionó por el retraso en los libros de comercio, la ausencia de hechos en la contabilidad, el desvío de operaciones por cuenta propia, el desvío de activos de los clientes y la indebida aplicación de fondos ${ }^{21}$. Lo relevante de la época es que en 2000, en Curazao, un paraíso fiscal, se creó subrepticiamente la firma Fondo Premium Capital, de la cual Interbolsa era comisionista y cumplía encargos de corresponsalía, según acuerdo formal entre ellas. Más adelante, Juan Carlos Ortiz, tras dejar Interbolsa, fundó Proyectar Valores. Pero lo que cambió el rumbo de las cosas fue la aparición de Alessandro Corridori, un italiano que recomendó la diversificación de negocios por medio de una holding. Así, los servicios financieros quedaron multilateralizados en tres rubros: a) inversiones estratégicas, b) inversiones de capital e, c) inversiones de tesorería. En la primera, las inversiones estaban circunscritas en Acercasa Seguros, comisionista de bolsa; Interbolsa Brasil; Interbolsa Panamá; Interbolsa Securities; Fundación Interbolsa; Interbolsa Special Situation; el círculo de inversiones de la segunda comprendió Easy Fly, Grupo EMI, Tribeca Fund One, Bolsa de Valores Colombia, Odinsa y las firmas claves del colapso financiero Coltejer y Fabricato; finalmente, por la tercera, los directivos de Interbolsa decidían la colocación de inversiones en mercados internacionales y locales sobre la base de una mesa de dinero. Todo esto cerró un amplio círculo de operaciones bursátiles.

El colapso de la organización fue marcado a principios de 2010 con la adquisición del 30\% de las acciones de Fabricato. Como

19 La posición propia no es la única línea de negocios. Es la más importante, sí. Pero, además, hay otras. En efecto, después de aquella están la banca corporativa y privada, la administración de carteras colectivas, la banca de inversión, las inversiones internacionales. La última línea abierta fue la de giros y remesas, que no tuvo el éxito de las primeras.

20 Infra, II.

21 Norbey Quevedo, Interbolsa: la debacle anunciada. La liquidación de la sociedad, El Espectador (11 de noviembre de 2012). Disponible en: http://www.elespectador.com/noticias/investigacion/ interbolsa-debacle-anunciada-articulo-386382 
informó un periódico local, ese fue el comienzo del fin del poderoso imperio bursátil de Interbolsa ${ }^{22}$. En efecto, esas adquisiciones dispararon el precio de las acciones de Fabricato. Pero como las operaciones descansaban en la dinámica de los repo, es decir, con base en préstamos que tenían por garantía solo las mismas acciones (títulos en apariencia respaldados con liquidez), se llegó a un punto en que el precio de las acciones no podía subir más. Por detrás de la aparente formalidad de las operaciones, lo cierto es que no había liquidez. Esto afectó el cumplimiento de pago de las distintas deudas. Una de ellas, la detonante, fue la del BBVA, banco al que Interbolsa no le pudo pagar $\$ 20.000$ millones. Esta situación encendió todas las alarmas del mercado bursátil. Fue entonces cuando intervino la Superintendencia Financiera, que por Resolución 1812 de 7 de noviembre de $2012^{23}$ dio a conocer la liquidación administrativa forzosa de Interbolsa.

Tras esto, se supo incluso que la falta de cumplimiento de pagos no solo fue al BBVA, sino además a la Clínica Candelaria, de la que, días antes del colapso, recibió un préstamo por más de US $\$ 41$ millones, que Interbolsa garantizó con acciones de Easy $\mathrm{Fly}^{24}$, es decir, todo un círculo de operaciones económicas viciadas en bolsa.

22 Norbey Quevedo, Interbolsa: la debacle anunciada. La liquidación de la sociedad, El Espectador (11 de noviembre de 2012). Disponible en: http://www.elespectador.com/noticias/investigacion/ interbolsa-debacle-anunciada-articulo-386382

23 Superintendencia Financiera, Resolución 1812 de 2012, por la cual se ordena la liquidación forzosa administrativa de la sociedad comisionista de bolsa INTERBOLSA S.A., 7 de noviembre de 2012. Disponible en: http://actualicese.com/normatividad/2012/11/07/resolucion1812-de-07-11-2012/

24 Una de las principales razones que marcaron el punto de quiebre de Interbolsa fue la adquisición de Fabricato, la textilera antioqueña que no estaba manejada por grandes accionistas. Pero esta adquisición se hizo no por la vía convencional, que habría sido una oferta pública de acciones (OPA), sino por la vía subrepticia de poner en marcha operaciones de reporto. Según Alberto Donadío, comprar Fabricato a un precio muy bajo y luego venderlo a su valor real era un buen negocio, como se dijo antes, siempre que se hubiera optado por la vía convencional. Eso fue precisamente lo que no se hizo, y se optó más bien por los repo. Con esa lógica, Corridori convenció a Interbolsa de adquirir las acciones de Fabricato. Así las cosas, según la revista Semana, de cada $\$ 100$ en acciones de Fabricato, Interbolsa le prestaba $\$ 60$ que conseguía en el mercado, los $\$ 40$ restantes los ponía Corridori como garantía; ese nivel de garantía lo establecía la propia Bolsa de Valores de Colombia, dependiendo de la liquidez de cada acción. Y como los informes de auditoría y los informes económicos eran buenos, la confianza en la ejecución de la operación era positiva. Sin embargo, la primera de las infracciones fue que la adquisición de acciones se ejecutó sin contar con la autorización de los accionistas de Interbolsa, hecho que no fue aislado, sino que se replicó repetidas veces, y no solo con esos accionistas, sino con otros que la comisionista buscó en el mercado. A la hora del cumplimiento de las obligaciones, Corridori no honró la deuda; luego, Interbolsa se vio obligada a responder en consecuencia frente a sus accionistas y acreedores. Como no había dinero, empezó el descenso de la firma. 


\section{B. La puesta en evidencia de la insuficiencia de la norma y los ámbitos de responsabilidad}

De todo ello, en la actualidad se urden distintas imputaciones de responsabilidad; se ha señalado incluso a autoridades públicas y políticas, entre ellas al Presidente de la Nación, a la Superintendencia Financiera y a la Bolsa de Valores de Colombia. De esta última, Alberto Donadío ${ }^{25}$ ha argumentado que la Bolsa - más que cumplir su función de vigilar y evitar la formación de burbujas financieras - se interesó por el margen de las comisiones; lo que la convierte, entre otras cosas, en la protagonista principal de la crisis de Interbolsa.

Sea cual fuere el margen de responsabilidad política y/o jurídica, este supuesto de hecho ha sacado a la luz o ha puesto al descubierto la ausencia de un efectivo mecanismo de control y vigilancia de las instituciones públicas y, junto a ello, la falta o insuficiencia de normas jurídicas de orden punitivo (derecho penal y administrativo) y preventivo (derecho privado patrimonial) en el ordenamiento jurídico colombiano.

A estos efectos, no debe perderse de vista que la regulación legal del Estatuto Anticorrupción, que modifica el Código Penal' ${ }^{26}$, es sancionado recién en 2011, y no hay prognosis, de otro lado, de producción o modificatorias de normas de derecho privado, orientadas a la corrección de operaciones de actividades de mercado en busca de sentar un escenario de confianza de las transacciones económicas ${ }^{27}$.

Otra de las consecuencias en cadena del desastre financiero fue la caída de la sociedad Fondo Premium, aquella con sede en Curazao, Antillas Holandesas; tras la insolvencia de Interbolsa, se produjo también su derrumbe. Esto confirmaba que aquella había sido creada para canalizar todas aquellas operaciones bursátiles desde la sombra, desde ese paraíso fiscal, su tarea descansaba en el eje de captar dinero, encauzarlo en diversas inversiones y luego retornarlo a Colombia por medio de los repo que, como se dijo antes, no tenían el consentimiento de sus titulares, los accionistas.

25 Alberto Donadío, El cartel de Interbolsa. Crónica de una estafa financiera, 136 (Sílaba Editores, Bogotá, 2013).

26 Ley 599 de 2000, por la cual se expide el Código Penal. Disponible en: http://www.alcaldia bogota.gov.co/sisjur/normas/Norma1.jsp?i=6388

27 Un interesante examen del caso Interbolsa mediante la instrumentalización del contrato de corresponsalía es el de Néstor Rodríguez, quien señala que el origen de la caída de Interbolsa fue la inconclusión de la estrategia diseñada por sus mentores para obtener utilidades a partir de los dineros del público realizando operaciones bursátiles riesgosas. Entre ellas, se intentó adquirir Fabricato para una posterior venta. El estímulo para ello era que el valor de las acciones en el mercado era mucho menor que el verdadero. Las operaciones requerían 


\section{USO DE CATEgorías DE DERECho PRIVAdo}

La presencia de intereses privados económicos como pilar esencial de la economía de la transgresión provoca necesariamente la utilización de instrumentos o instituciones jurídico privadas para la comisión de actos de corrupción y encubrimiento, desviación y ocultación de beneficios ilícitos derivados de los mismos. Es lo que podemos calificar como un uso perverso de las instituciones del Derecho privado ${ }^{28}$.

Si se ve detenidamente las cosas, los resultados financieros nocivos de Interbolsa y cualquier otra sociedad anónima cotizada en el mercado bursátil tiene por punto de partida la inconducta interna de directivos en la gestión de empresas privadas, quienes para lograr esos ilícitos aprovechan lagunas legales del sistema, defectos estructurales de las corporaciones y fallas del sistema financiero en general, entre otras cosas. Y lo hacen tanto en beneficio propio como de personas asociadas a la red de corrupción, sobre la base del abuso de poder de decisión empresarial y la ruptura de confianza de sus accionistas y empresarios, que conjuga o maquilla con el interés público.

Se sabe que para alcanzar esos ilícitos, por los rastros que dejan los procesos de inculpación, es necesario utilizar instituciones de

dinero del público, para lo cual entran en juego los contratos de corresponsalía, los cuales se usaron para recibir dinero de los inversionistas colombianos y financiar esas estrategias ilícitas. Según refiere el autor, quien extrae información de la revista Dinero, lo más escandaloso fue descubrir que las dos personas promotoras de la operación desde el año 2000 no solo crearon la sociedad en Curazao para la captación de estos recursos sino que ellos mismos designaron la firma Eclipse, como gerente en Curazao, y esta firma los nombró a su vez investment advisors, es decir, responsable de decidir sobre las inversiones del fondo. Con todo, el autor sugiere que hace falta una regulación de los servicios y productos financieros sobre la base de supervisiones periódicas y criterios técnicos para las obligaciones de informar, la exclusión de paraísos fiscales que no posean reglas de supervisión mínimas, y algo arriesgado: la facultad de la Superintendencia Financiera de Colombia, SFC, para revocar la autorización de un contrato de corresponsalía cuando verifique incumplimientos normativos. NÉSTOR Rodríguez-Rodríguez, El contrato de corresponsalía y su papel en el caso Interbolsa, XVII Revista Prolegómenos, 34, 123-145 (2014). Disponible en: http://www.redalyc.org/articulo. oa?id $=87633272008$

28 Fernando Carbajo, Corrupción en el sector privado (I): la corrupción privada y el derecho privado patrimonial, 10 Iustitia, 281-342, 307 (2012). Disponible en: http://www.ustabuca.edu. co/gpresenzia/vista/tpl/ustabmanga/revista-iustitia.html. Carbajo arguye también que los instrumentos del derecho privado propios para la circulación de la riqueza son utilizados para dar apariencia de legalidad a operaciones ilícitas de ocultación y desviación de activos o fondos públicos o privados, en los cuales aparece siempre como requisito casi indispensable la creación de uno, varios o muchos entes instrumentales, tras los que se esconden directa o indirectamente los beneficiarios de las operaciones de corrupción. 
derecho privado con el fin esencial de darles apariencia de legalidad. Entre estas, están instrumentos de derecho societario y empresarial, contractual y de obligaciones y derecho de la competencia, básicamente.

De acuerdo con ello, en esta sección, se revisarán dos de estos instrumentos: el primero, las sociedades encubiertas y, el segundo, los repo u operaciones de reporto.

\section{A. Sociedades encubiertas}

Para las operaciones de desvío de fondos privados, resulta inevitable la creación de una o más empresas instrumentales (susceptibles de control y manipulación). Por lo general en forma de sociedades de capital, anónimas y limitadas, lo que no excluye fundaciones, cooperativas o asociaciones sin fines de lucro. La finalidad de esas sociedades yace en el ámbito de lo ilícito, pues sus operaciones de mercado vienen cubiertas con el manto de apariencia de legalidad, que brinda el derecho societario.

La realidad del mercado trae una serie de ellas, que se han diversificado en distintos tipos societarios a falta de regulación local o global, en particular en países no industrializados y a causa de los efectos de la globalización económica.

En esta parte del trabajo, no se identificarán todas las formas societarias sino solo alguna de ellas, que se consideran relevantes para el análisis. A estos efectos, se seguirá la división de Javier Carrascosa-González ${ }^{29}$ respecto de las sociedades en ámbito del derecho internacional privado, que son: sociedades off-shore, sociedades de baja intensidad, sociedades fiduciarias auténticas y, por último, sociedades fiduciarias en manos de figureheads, testaferros o sociedades puramente instrumentales ${ }^{30}$, sin dejar de lado la referencia a las sociedades fantasma ${ }^{31}$.

29 JaVier CARrascosa-GonzÁlez, Sociedades fantasma y derecho internacional privado, 27 Revista Electrónica de Estudios Internacionales, REEI, 1-54, 4 (2014). Disponible en: http://www.reei. org/index.php/revista/num27/articulos/sociedades-fantasma-derecho-internacional-privado

30 JaVier Carrascosa-GonzÁlez, Sociedades fantasma y derecho internacional privado, 27 Revista Electrónica de Estudios Internacionales, REEI, 1-54, 4 (2014). Disponible en: http://www.reei. org/index.php/revista/num27/articulos/sociedades-fantasma-derecho-internacional-privado

31 JaVIER CARrascosa-GonzÁlez, Sociedades fantasma y derecho internacional privado, 27 Revista Electrónica de Estudios Internacionales, REEI, 1-54, 4 (2014). Disponible en: http://www.reei. org/index.php/revista/num27/articulos/sociedades-fantasma-derecho-internacional-privado 


\section{Sociedades off-shore}

Lo relevante de este tipo de sociedades es que fijan su sede social en un paraíso fiscal con el objetivo de beneficiarse de las ventajas tributarias y mercantiles que les brinda la legislación de ese país. En razón de sus actividades, estas pueden ser de dos clases: una, las que no realizan actividades en su sede social; y otra, las que realizan cuando menos una actividad económica en su sede social. En el caso de la primera, las actividades son desencadenadas particularmente en el país donde residen los socios. En este supuesto, la creación de la sociedad que los responsables de Interbolsa denominaron Sociedad Fondo Premium, cuya sede social estaba en Curazao, esto es, sometida a las reglas de derecho societario de las Antillas Holandesas, pero sus actividades de captación de recursos y activos estaban dirigidas a territorio colombiano por medio de la comisionista Interbolsa.

Entre las ventajas fiscales que ofrecen estos tipos societarios están la de una administración ágil, la constitución de una posibilidad ilimitada de sociedades unipersonales, la exoneración de presentación de cuentas anuales (lo cual deja por fuera las auditorías), la confidencialidad de la titularidad de los fundadores o socios de la sociedad (esa información no obra en registros públicos) y dan, entre otras cosas, la posibilidad legal de utilizar fiducias para la dinámica de sus actividades económicas.

Como apunta Fernando Carbajo ${ }^{32}$ : "tras ellas se esconden directa o indirectamente los beneficiarios de las operaciones de corrupción", de ordinario enmarcados en redes organizadas de conglomerados de sociedades o entes instrumentales, mediante cuyos cauces económicos se hace circular dinero ilícito con la finalidad de borrar la pista de su origen y, en su caso, despitar las investigaciones ${ }^{33}$.

En ámbito del derecho privado, la movilidad de esos fondos ilícitos se canaliza por contratos simulados, cuyo soporte de facturas

32 Fernando Carbajo, Corrupción en el sector privado (I): la corrupción privada y el derecho privado patrimonial, 10 Iustitia, 281-342, 312 (2012). Disponible en: http://www.ustabuca.edu. co/gpresenzia/vista/tpl/ustabmanga/revista-iustitia.html

33 En este punto argumenta, el autor que las sociedades instrumentales se combinan habitualmente con el recurso a testaferros en los puestos de socio y de administración, con lo queda en la sombra el auténtico responsable y beneficiario de la operación fraudulenta, esto es, el dominus societatis. 
es falso; y son diseñados bajo una doble misión: primero, extraer dinero de fondos públicos o privados y, segundo, movilizarlos por medio de la red de sociedades del mismo conglomerado empresarial $^{34}$.

\section{Sociedades de baja intensidad}

Esta es una sociedad en permanente situación de impago y quiebra técnica. No ha desaparecido del mercado. Existe. Pero por voluntad de sus socios, se mantiene en régimen de baja actividad económica. Lo relevante es que a fin de mantener vigente el objeto social de la empresa en el mercado, los administradores hacen nacer otra sociedad, una paralela, si se quiere. Así, se manejan dos, una con actividades empresariales de riesgo en el mercado y otra con actividades casi cero. La finalidad de ello es blindarse de molestos acreedores, y lavar la imagen y el renacimiento de la otra sociedad; además, claro está, de ser destino de operaciones económicas calculadas.

\section{Sociedades fiduciarias auténticas}

Una sociedad fiduciaria auténtica tiene por objeto la administración o gestión de un patrimonio económico que recibe de manos de un fiduciante o transmitente de derechos con la obligación de transmitirlo o restituirlo a favor del mismo fiduciante o de un tercero beneficiario, según las estipulaciones del acuerdo entre sociedad y fiduciante.

La novedad en el ámbito de la globalización de mercados es que las sociedades fiduciarias se localizan en paraísos fiscales. Y de acuerdo con la dinámica de corrupción, que es objeto de este examen, la fiduciaria tiene una sola misión: la actividad de pura gestión social, esto es, administrar activos, realizar no solo pagos, sino inversiones de capital en bolsa, gestionar una cartera de valores y representar los intereses de los tenedores de títulos valores, entre otros actos análogos.

34 Una buena muestra de las actividades ilícitas de un conglomerado de sociedades instrumentales puede verse en España en el caso Banesto. España, caso Banesto, Sentencia 867/2002, del Tribunal Supremo, Segunda Sala Penal, 29 de julio de 2002. Disponible en: http://estaticos. elmundo.es/especiales/2002/07/economia/conde/1a100.pdf 
En la línea de los ilícitos, estas sociedades pueden realizar no solo operaciones legítimas, sino además encubiertas con apariencia de legalidad. En su origen, la razón de su constitución no descansa en la finalidad de bloquear a los acreedores de las exigencias de pago, sino que tal suceso es sobrevenido, por ejemplo, con la formación de patrimonios separados $\mathrm{y}$, en ese orden, tampoco pertenecen a personas, que previamente las hayan diseñado para tal entuerto.

\section{Sociedades fiduciarias de testaferros o puramente instrumentales}

Son sociedades fiduciarias creadas en paraísos fiscales a favor del fiduciante con la única finalidad de burlar el cumplimiento de obligaciones de pago y protegerlo, en consecuencia, de embargos, ejecuciones patrimoniales y pago de impuestos.

Desde el origen, la finalidad yace en lo ilícito. La razón fundamental de su creación no es otra que transferir ficticiamente activos a favor de la fiduciaria constituida. Se crea, en este sentido, un patrimonio separado del fiduciante (una persona natural o una sociedad) que en apariencia pertenece a la fiduciaria.

Lógicamente, la transferencia de activos se instrumenta mediante contratos de compraventa, cesión de créditos, cesión de derechos y otros análogos con la particularidad de que todos ellos son simulados. Esto es, que no hay transmisión real de activos. Quien aparece frente a los acreedores del fiduciante es amigo de este (fiducia cum amico) o figurehead, como se le conoce en derecho anglosajón, o comúnmente llamado también testaferro del propietario legítimo.

El círculo de operaciones se cierra con la transferencia de ganancias del testaferro a favor del verdadero titular de los bienes y se ejecuta por vías de hecho o por contratos ocultos o pactos secretos que, tras las cortinas de legalidad que dan los paraísos fiscales, difícilmente son observables.

En suma, se trata de sociedades utilizadas como medio o instrumento legal para alcanzar fines que rozan lo ilícito. 


\section{Sociedades fantasma}

Por último, corresponde identificar las sociedades fantasma. A diferencia de las anteriores, en este caso, se trata de una sociedad que solo tiene un apartado de correos o buzón para recibir cartas (Letterbox, como se le conoce en ámbito anglosajón) y, por ende, no desarrolla ninguna actividad social. Esta sociedad no siempre se constituye en paraísos fiscales, puede organizarse en Estados que ofrezcan algunas ventajas apetecibles a sus fines, básicamente fiscales. Y lo relevante de su existencia es que están desconectadas jurídicamente de sus creadores, dada la deslocalización de su sede respecto de la de sus socios o creadores; de modo que esta no es una sociedad off-shore, como la que se ha apuntado líneas arriba ${ }^{35}$.

Se acude a este tipo de sociedad y a todas las anteriormente examinadas con el único objetivo, como apunta Carbajo ${ }^{36}$, de canalizar, mover e invertir fondos provenientes de operaciones ilícitas, en muchas ocasiones, para evitar el trámite de constitución de sociedades auténticas, dado que ellas dejan rastros en razón de los controles notarial y registral respectivos ${ }^{37}$.

\section{B. Operaciones de reporto}

Si seguimos literalmente lo que señala el artículo 1 del Decreto 4432 de 2006, las operaciones de reporto o repo:

35 Supra, II.

36 Fernando Carbajo, Corrupción en el sector privado (I): la corrupción privada y el derecho privado patrimonial, 10 Iustitia, 281-342, 313 (2012). Disponible en: http://www.ustabuca.edu. co/gpresenzia/vista/tpl/ustabmanga/revista-iustitia.html

37 Fernando Carbajo señala además que por medio de este tipo de sociedades, en especial las instrumentales, es posible la compra de acciones a bajo precio de una sociedad anónima o limitada que existe en el mercado pero no ejecuta actividad real alguna (las denominadas compras de capa o Mantelkauf, en derecho alemán), en busca a tal efecto de sociedades relacionadas con la empresa privada en las que actúan quienes quieren llevar a cabo actos de corrupción. Siguiendo nuestro análisis, todo ello no es más que una muestra que encaja con la dinámica de las operaciones fabricadas por la red de Interbolsa y sus sociedades serviles. Llama la atención, por último, el asesoramiento jurídico que existe y se ofrece a este tipo de organizaciones. Según Carbajo, actualmente hay corporaciones de abogados especializados en la compraventa de sociedades, incluso a la carta. No es esta una actividad ilícita. Pero en ocasiones se hace de ella un uso perverso por parte de los abogados (y de las instrucciones de los empresarios) que buscan canalizar fondos ilícitos hacia terceros países. No solo ello, el desvío también puede ser de fondos lícitos, esto es, un supuesto de fuga de capitales. Para todo esto, es muy habitual que en paraísos fiscales (Gibraltar, Andorra, Lichtenstein...) el número de sociedades domiciliadas supere tres veces el número de personas naturales censadas. 
son aquellas en las que una parte (el enajenante), transfiere la propiedad a la otra (el adquirente) sobre valores a cambio del pago de una suma de dinero (el monto inicial) y en las que el adquirente al mismo tiempo se compromete a transferir al enajenante valores de la misma especie y características a cambio del pago de una suma de dinero (monto final) en la misma fecha o en una fecha posterior previamente acordada ${ }^{38}$.

Si se ve detenidamente, en este tipo de operación financiera hay una doble transferencia de valores: en un primer momento, la del enajenante a favor del adquirente y, en segundo momento, la del adquirente al enajenante. El objeto de la negociación son valores de mercado, generalmente acciones, que en el intercambio pueden ser de la misma especie y características, lo que no obsta para que sean las mismas, además de que las contraprestaciones en ambos extremos sean las de dar suma de dinero. Stricto sensu, son obligaciones recíprocas en las cuales las partes asumen las posiciones de acreedor y deudor a la vez. La particularidad, por último, descansa en que el intercambio u observancia de las obligaciones puede ejecutarse el mismo día del acuerdo.

Por estas cuestiones, la figura puede ajustarse a un acuerdo de venta con pacto de retroventa, en razón de que cabe la posibilidad de que el enajenante recupere los valores entregados, siempre que el adquirente devuelva los mismos como parte de su contraprestación, además siempre que ese enajenante haya cumplido su obligación de pago, entretanto esos valores quedan en garantía ${ }^{39}$.

No debe perderse de vista que la particularidad más relevante reposa en que el inversionista que adquiere el título queda facultado para transferirlo o negociarlo en el mercado de valores, obviamente antes del vencimiento de la obligación.

38 Decreto 4432 de 2006, por el cual se dictan disposiciones sobre las operaciones de reporto o repo, simultáneas y transferencia temporal de valores, 46.479 Diario Oficial, 11 de diciembre de 2006. Disponible en: http://www.alcaldiabogota.gov.co/sisjur/normas/Norma1.jsp?i=22403\#0

39 En relación con el pacto de retroventa, la Superintendencia Bancaria de aquel entonces la regulaba en este sentido, según la Circular 58 de 1988. Lógicamente, esto ha ido mutando. Incluso en la actualidad, tras el desastre de Interbolsa, las operaciones repo tienen nueva regulación, la del Decreto 2878 de 2013, mediante la cual se busca garantizar el cumplimiento de las obligaciones derivadas de este tipo de operaciones bursátiles. Decreto 2878 de 2013, por el cual se modifica el Decreto 2555 de 2010 en relación con las operaciones de reporto o repo, simultáneas y transferencia temporal de valores y se dictan otras disposiciones. Disponible en: http://wsp.presidencia.gov.co/Normativa/Decretos/2013/Documents/DICIEMBRE/11/ DECRETO \%202878\%20DEL\%2011\%20DE\%20DICIEMBRE\%20DE\%202013.pdf 
No obstante, de acuerdo con Leonel Ariza ${ }^{40}$, no está clara la verdadera naturaleza jurídica de los contratos de reporto, dado que se han planteado distintas tesis: desde la doble venta hasta el pacto con retroventa, pasando por el acuerdo de prenda sin tenencia ${ }^{41}$. $Y$ en ello tiene razón, el autor; especialmente por los más recientes acontecimientos en el mercado bursátil colombiano, no solo los de Interbolsa, sino por los ajustes y modificatorias legislativas.

Si bien la discusión sobre el reporto está hundida en las farragosas elucubraciones conceptuales acerca de su naturaleza jurídica, como ocurre con la mayoría de categorías de derecho; sin embargo, su finalidad económica está clara: la de "permitir que el dueño de unos títulos de contenido crediticio o de unas acciones pueda obtener liquidez transitoria mediante la utilización de esos activos, sin tener que venderlos definitivamente" 42 .

Para terminar, y especialmente con el objeto de que se vea con claridad la utilización de esta categoría contractual por la red de actividades ilícitas de Interbolsa, que es replicable a sociedades con fines análogos, consideramos pertinente ilustrar cómo una operación repo se convierte en una estrategia de especulación en el mercado bursátil, para lo cual seguimos la línea de explicación de Leonel Ariza, quien alega que con la formalización de estos acuerdos es posible para un sujeto "adquirir más acciones de las que realmente podría comprar con el dinero que efectivamente tiene" ${ }^{\prime 3}$. Todo esto se realiza con la expectativa de que el precio de las acciones suba en el futuro y le permita maximizar exponencialmente esa utilidad.

\section{Imagine la siguiente hipótesis:}

Una persona desea invertir en bolsa. Para ello, tiene un capital de $\$ 50$ millones. Si decide comprar acciones de la manera tradicional, y suponiendo que cada acción vale $\$ 1.000$, obtendrá 50.000

40 Leonel Ariza, El reporto, 27 (Ediciones Pontificia Universidad Javeriana, Bogotá, 2012).

41 Leonel Ariza, El reporto, 33 (Ediciones Pontificia Universidad Javeriana, Bogotá, 2012).

42 Leonel Ariza, El contrato de reporto o las famosas operaciones repo, Portafolio (21 de abril de 2014). Disponible en: http://www.portafolio.co/opinion/blogs/el-coloquio-juridico/el-contratoreporto-o-las-famosas-operaciones-repo-parte-i

43 Leonel Ariza, El contrato de reporto o las famosas operaciones repo, Portafolio (21 de abril de 2014). Disponible en: http://www.portafolio.co/opinion/blogs/el-coloquio-juridico/el-contratoreporto-o-las-famosas-operaciones-repo-parte-i 
acciones. Hasta aquí no hay nada nuevo. Pero si se decide por una repo, obtendría hasta 160.000 acciones, de la siguiente manera: invierte en bolsa esas 50.000 acciones mediante la celebración de una operación repo con la finalidad de obtener dinero prestado hasta el 70\% del capital invertido (máximo permitido por la BVC), que sería $\$ 35$ millones. Una vez obtenida esta cantidad, los vuelve a invertir para la compra de más acciones, y si se mantiene el precio de $\$ 1.000$ por cada acción, al final de la operación tendría 35.000 acciones. Luego, nuevamente, con la inversión de este número de acciones obtendría en dinero $\$ 24,5$ millones, lógicamente con una nueva repo. Y así sucesivamente hasta comprar la cantidad de 160.000 acciones. Ahora bien, si uno se detiene a ver estos números, nuestro inversionista empezó con solo 50.000 acciones respaldadas, el resto - las 110.000 acciones - supone deudas que tendría que cumplir pagándolas. En dinero, eso es \$110 millones, que si las cosas van bien en la bolsa pueden tranquilamente ser pagados. Para ello, lo único que habría que esperar es que las acciones suban en cualquier cifra por encima de $\$ 1.000$. Y suponiendo que suben a $\$ 1.100$, nuestro inversionista - vendiendo todas sus acciones y descontando las tasas de intereses respectivas - obtendría en 30 días (plazo al que supongamos se hayan pactado los repo) la suma de dinero en efectivo de \$17 millones, lo cual sumado al capital inicial y a la anualización de la rentabilidad daría una suma astronómica, partiendo tan solo de $\$ 50$ millones.

Esa es la lógica que ha sido utilizada, en especial en la adquisición de valores de Fabricato. Claro, con la particularidad de la pérdida de credibilidad de las acciones de ese conglomerado de sociedades, que las convirtieron en un rosario de especulaciones bursátiles ${ }^{44}$.

44 Se muta así su verdadera naturaleza económica que es la de solventar liquidez transitoria a los patrimonios de los sujetos contractuales en torno a las vicisitudes de la dinámica de los mercados bursátiles, y en torno a las obligaciones que desencadena el contrato de reporto. 


\title{
III. MATERIALES PARA LA SOLUCIÓN DE LA CORRUPCIÓN DESDE LA ÓPTICA DEL DERECHO COMPARADO
}

\begin{abstract}
La corrupción es algo bastante habitual en España, pero también en otros países. La diferencia es que en mercados como el anglosajón hay una actitud mucho más decidida a combatir estas prácticas. Es una lacra para la sociedad. Genera desigualdades e inseguridad jurídica y hace que aumenten los costes porque hay que pagar más para conseguir lo mismo ${ }^{45}$.
\end{abstract}

Como se dijo al principio de este trabajo, el supuesto de corrupción en el sector privado o público no tiene exclusividad territorial; este se presenta tanto en países industrializados como en los que no lo son. La diferencia radica en la aplicación de reglas jurídicas y políticas, y no tanto en su diseño o construcción. Como señala Antonio Argandoña ${ }^{46}$, no estamos ante un fenómeno exclusivo de países ricos o pobres, de economía de mercado o de planificación central, grandes o pequeños, democráticos o no: la corrupción está presente en todo el mundo y es objeto de distintas explicaciones ${ }^{47}$, las cuales, en su caso (en relación con estas últimas), logran ser recogidas en reglas orientadas hacia la corrección de esas conductas.

Más allá de la eficacia a la hora de la aplicación de tales reglas, incluso de las que son de orden ético, en la actualidad se buscan están-

45 David Fernández, La corrupción es un baile de dos, El País (21 de diciembre de 2014). Disponible en: http://economia.elpais.com/economia/2014/12/18/actualidad/1418926974_691303.html

46 Antonio Argandoña, La corrupción y las empresas, 0-10 (IESE Business School, Universidad de Navarra, Occasional Paper OP-07/21, 2007). Disponible en: http://www.iese.edu/research/ pdfs/OP-07-21.pdf

47 Agrega Antonio Argandoña que se trata de un fenómeno polifacético de numerosas variantes y que, por tanto, ha sido y es objeto de distintos puntos de vista. Y no es una enfermedad única, sino, en todo caso, el síntoma de males profundos de la economía, la política, la sociedad y la moral en todo el mundo. El objetivo ha de ser, por tanto, no de perseguirla directamente sino de conseguir que todos los países del mundo tengan gobiernos, administraciones, empresas y ciudadanos honrados y eficientes, que actúen siempre con criterios éticos.

Un aspecto importante es saber cuáles son las causas de la corrupción, a estos efectos, Antonio Argandoña manifiesta que la corrupción es el resultado de tres factores: oportunidad, beneficio y riesgo. Así las cosas, la concentración de poder de decisión en una persona, sin un control suficiente, crea la oportunidad. El beneficio deriva de los ingresos que puede obtener el corrupto, que estarán relacionados con los beneficios o costos que puede hacer recaer sobre el que paga. Y el riesgo viene dado por las posibilidades de que la corrupción sea descubierta y por la dureza del castigo. Es, sin duda, una explicación práctica de las cosas, desde el ángulo de la economía y el comportamiento racional del individuo, lo que no excluye otras posibilidades de argumentación. 
dares de derecho o estructuras de derecho estables ${ }^{48}$ a escala global, que hagan frente a los actos de corrupción privada o pública que, tras la globalización de los mercados, se han extendido de manera dramática.

En este sentido, el primero de los materiales de derecho a tomar en consideración es la Convención de Naciones Unidas contra la Corrupción ${ }^{49}$ : el instrumento global más relevante no solo de lucha, sino de prevención contra la corrupción, con base en un amplio consenso internacional. En este mismo nivel de importancia, se sitúa el Pacto Global Anticorrupción, de $2004^{50}$, derivado de una iniciativa internacional de Naciones Unidas, que busca la adhesión voluntaria de corporaciones privadas sobre la base del reconocimiento e incorporación de 10 principios en sus actividades empresariales a escala nacional y global, los cuales giran en torno a derechos humanos, laborales, medioambientales y anticorrupción.

Con el fin de ir cerrando el círculo de reglas apropiadas para mitigar los supuestos de corrupción, y quedarnos solo con un puñado de ellas, corresponde hacer mención a herramientas que, muy a pesar de la buena intención con las que han sido diseñadas, no han resultado eficaces a la hora de su aplicación práctica, lo cual nos lleva a un razonamiento empírico negativo de ellas, especialmente desde la óptica de su solitaria pugna contra la corrupción: unidisciplinar, si se quiere. No quiere decir ello que no aporten a disipar los índices de corrupción sino que, como apunta Carbajo:

(...) se hace necesario algo más que un compromiso de honorabilidad, buen gobierno y responsabilidad social empresarial en el desarrollo de actividades económicas privadas, y algo más también que la abstracta definición de deberes de diligencia o deberes fiduciarios de gestores ${ }^{5 l}$.

Así las cosas, si bien en un primer momento el control de la corrupción se redujo a instrumentos de Códigos de Buen Gobierno

48 John Alberto Tito-Añamuro, Modernización e integración del derecho contractual latinoamericano. Un análisis del método, 16 (Grupo Editorial Ibáñez, Ediciones Uninorte, BogotáBarranquilla, 2012).

49 Organización de Naciones Unidas, Convención de Naciones Unidas contra la Corrupción, Resolución 58/4 de la Asamblea General de Naciones Unidas, 31 de octubre de 2003, en vigor desde 2005. Disponible en: http://www.unodc.org/pdf/corruption/publications_unodc_convention-s.pdf

50 Organización de Naciones Unidas, Los diez principios del Pacto Global, 2004. Disponible en: http://www.pactomundial.org/, https://www.unglobalcompact.org/

51 Fernando Carbajo, Corrupción en el sector privado (I): la corrupción privada y el derecho 
y a los de Responsabilidad Social de la Empresa, la experiencia ha demostrado que, pese a la puesta en vigencia de esas reglas, las prácticas fraudulentas del poder empresarial han ido, como dirían los italianos, in crescendo, y al lado de ellas las del mal funcionamiento también del mercado financiero.

En consecuencia, afrontar el problema de la corrupción con nuevas reglas, y con eficacia, supone un basta ya al artificio de los Códigos de Autorregulación: de prácticas empresariales, de buen gobierno de los directivos o de transparencia de mercados financieros. Se precisa, en efecto, como apunta Carbajo algo más que un mero compromiso de honorabilidad ${ }^{52}$. Desde nuestra óptica, se ha de ajustar a una justicia contractual que realmente neutralice las consecuencias negativas de esos actos nocivos con base en reglas concretas, y se haga además desde una perspectiva interdisciplinar. Esto no está alejado de la realidad, si se ven los modelos de derecho de lucha contra la corrupción, en especial de los Países Bajos, como se deduce de los informes de Transparencia Internacional ${ }^{53}$.

En tal sentido, desde una perspectiva interdisciplinar, corresponde buscar apoyo en otras áreas del conocimiento, en especial jurídico; y lo primero que ha de traerse a colación, casi por inercia, son las normas punitivas del derecho penal, que en el sistema jurídico colombiano reposan en la Ley 1474 de mecanismos de prevención, investigación y sanción de actos de corrupción, de 2011, denominado Estatuto Anticorrupción de 2011 que, entre otras cosas, recoge sanciones para inconductas de trabajadores, accionistas, socios, revisores fiscales y directivos de sociedades privadas.

En nuestra opinión, no puede, sin embargo, dejarse la neutralización de todos los actos de corrupción a la exclusividad de las reglas punitivas del derecho penal, sino que debe anteponerse a la ejecución de estas un orden preventivo que esté recogido ya en reglas de derecho privado o de derecho administrativo, todo con la finalidad no de sancionar esos actos sino de neutralizarlos pre-

privado patrimonial, 10 Iustitia, 281-342, 289 (2012). Disponible en: http://www.ustabuca.edu. co/gpresenzia/vista/tpl/ustabmanga/revista-iustitia.html

52 Fernando Carbajo, Corrupción en el sector privado (I): la corrupción privada y el derecho privado patrimonial, 10 Iustitia, 281-342, 289 (2012). Disponible en: http://www.ustabuca.edu. co/gpresenzia/vista/tpl/ustabmanga/revista-iustitia.html

53 Deborah Hardoon \& Finn Heinrich, Global Corruption Barometer 2013 (Transparency International, Berlin, 2013). Disponible en: http://www.transparency.org/whatwedo/publication/ global_corruption_barometer_2013 
viamente, desde la búsqueda de transparencia tanto de los actos como de la información que nacen en los centros de decisión y de poder de las sociedades privadas ${ }^{54}$. Para todo lo cual, y a fin de andar sobre las losas de un orden preventivo, cabe recordar que las reglas del derecho penal son de ultima ratio.

Así las cosas, en estas líneas se desbrozarán uno a uno los materiales que podrían ser útiles para la reformulación de normas de derecho privado, siguiendo en este caso la estela del movimiento neorregulador en materia especialmente de derecho societario, bursátil, de auditoría y de responsabilidad; advirtiendo al lector que para tal ejercicio se han considerado dos cosas: primera, que el examen no es de todas las categorías de derecho privado, susceptibles de reforma; y segunda, que las propuestas de modificación vienen encadenadas en su mayoría a reglas de orden público, porque se trata de enfrentar la corrupción de perfil polifacético desde la interdisciplinariedad.

En este sentido, tales materiales se han organizado en cuatro grupos: uno relativo a las obligaciones y deberes de las sociedades de capital, en especial de las cotizadas en bolsa; otro a fortalecer la exigencia de obligaciones contables y de divulgación; luego otro relativo a remozar y precisar las reglas de auditoría de sociedades de bolsa, que involucra la cooperación internacional y además las de autonomía y contratación de auditores y; por último, un grupo relativo a delimitar los deberes de información de administradores y ampliar criterios de imputación en materia de responsabilidad incluso para administradores de hecho. Para todo ello, corresponde subrayar a favor del lector que la revisión y la agrupación no tienen carácter exhaustivo, ello se hará en un trabajo posterior bajo un análisis de fondo de las categorías de derecho que precisan ser adaptadas a la exigencia de los nuevos supuestos de hecho que trae la globalización de los mercados.

En consecuencia, los materiales de derecho privado que resultarían idóneos para mitigar los actos de corrupción corporativa, empiezan en este primer grupo por readaptar la legislación societa-

54 En definitiva, se trata de hallar un punto de equilibrio entre la eliminación de trabas a la iniciativa privada y la creación de medidas eficaces de control. Pero no se trata de retornar a la época de la intervención pública masiva ni de desprivatización de las empresas, mucho menos de aquellas que son estratégicas. Ello, muy a pesar de lo que señalen algunas opiniones y fuerzas políticas, que reclaman insistentemente una intervención pública: masiva y decisiva. 
ria, esto es, concretamente en fortalecer tres situaciones: primera, los deberes y responsabilidades de los administradores; segunda, las obligaciones de información a los socios y accionistas y; tercera, la transparencia de los órganos de las sociedades anónimas y limitadas. A estas debe agregarse otra, que consideramos relevante: la obligación de divulgación de información patrimonial y financiera con los mecanismos de internet. Este orden de corrección de conductas empresariales está recogido en Derecho español en un único texto que, entre otras cosas, reforma la legislación societaria y de auditoría así como la de transparencia de sociedades cotizadas (Ley de Sociedades de Capital 1/2010 55 ), texto que en la práctica no hace otra cosa que llevar al imperio de la ley, las sugerencias de Directrices europeas y de Recomendaciones de los Códigos de Buen Gobierno Corporativo. En tal sentido, estas últimas, por ejemplo, dejan de ser simples recomendaciones y se convierten en normas de exigibilidad jurídica.

Un segundo grupo de materiales de derecho privado llegaría a ser la inserción de medidas preventivas como las de reforzar la exigencia de obligaciones contables, esto es, por ejemplo, las de elaboración y presentación de cuentas anuales en las sociedades de capital, las de consolidación contable tratándose de grupos de sociedades, que tienen mayor incidencia en el tráfico especialmente bursátil, entre las más importantes. Ciertamente, estas medidas están relacionadas con normas de derecho público. No hay, en este sentido, un aislamiento de aplicación de las reglas de derecho, sino que, según se dijo antes, van unidas o son interdisciplinarias ante la resolución de un mismo problema. En derecho europeo, la modificatoria de estas obligaciones de orden contable es la consecuencia de la aprobación de Normas Internacionales de Información Financiera, mediante el Reglamento CE 1606/2002 del Parlamento Europeo y del Consejo ${ }^{56}$.

Un tercer grupo, casi en la misma línea del anterior, es la inserción de reglas de auditoría para sociedades que cotizan en mercados bursátiles. En este sentido, la prevención descansa en exigir a las

55 España, Real Decreto Legislativo 1/2010, de 2 de julio, por el que se aprueba el texto refundido de la Ley de Sociedades de Capital, 161 Boletín Oficial del Estado, BOE, 3 de julio de 2010. Disponible en: http://www.boe.es/buscar/act.php?id=BOE-A-2010-10544

56 Unión Europea, Reglamento CE 1606/2002 del Parlamento Europeo y del Consejo, relativo a la aplicación de normas internacionales de contabilidad, Bruselas, 19 de julio de 2002. Disponible en: http://eur-http://eur-lex.europa.eu/legal-content/ES/TXT/?uri=celex:32002R1606 
sociedades emisoras de valores en bolsa la creación de un comité de auditoría en su estructura de organización societaria; y con ello, conseguir transparencia de la información financiera y bursátil y evitar, en este orden, los efectos nocivos de las maniobras de Interbolsa y Ecopetrol, entre tantos otros casos. No solo ello. También resulta conveniente implementar algún tipo de mecanismo de cooperación internacional, así como se tiene formulado en la más o menos reciente Ley española 12/2010 de auditoría de cuentas ${ }^{57}$. Resulta, por último, relevante la neorregulación de la independencia de los auditores por un lado, y por otro, la contratación y rotación de los mismos, además de la prohibición de formar parte de los órganos de dirección de sociedades auditadas con algún intervalo de anterioridad y, en especial, el deber de publicitar informes de auditoría de entidades de interés público por internet.

Un cuarto grupo en relación con los administradores de las sociedades llega a ser la obligación del administrador de una sociedad que cotiza en bolsa de presentar y difundir un informe anual de gobierno corporativo, separado del informe de gestión que se acompaña a las cuentas anuales, además de la obligación de disponer de un sitio web para dar a conocer la información exigible según las normas del mercado de valores. De otro lado, han de reforzarse los deberes de lealtad del administrador y los deberes de guardar secreto, incluso después de cesar sus funciones. En materia de responsabilidad, corresponde reforzar los criterios de imputación para que se hagan extensivos a los administradores de hecho; al hilo de ello, debe reforzarse además la responsabilidad de los administradores por no promover la disolución de la sociedad en riesgo de descapitalización. Estas y otras formas de neutralizar los ilícitos de la corrupción corporativa son el efecto de la tendencia neorreguladora, que tiene por punto de partida los informes y estudios de países con más competitividad empresarial y desarrollo industrial y tecnológico que los latinoamericanos. En este bloque, se han tomado las referencias o alguna de ellas del

57 España, Ley 12/2010, de 30 de junio, por la que se modifica la Ley 19/1988, de 12 de julio, de Auditoría de Cuentas, la Ley 24/1988, de 28 de julio, del Mercado de Valores y el texto refundido de la Ley de Sociedades Anónimas aprobado por el Real Decreto Legislativo 1564/1989, de 22 de diciembre, para su adaptación a la normativa comunitaria, 159 Boletín Oficial del Estado, BOE, 1 de julio de 2010. Disponible en: http://www.boe.es/boe/dias/2010/07/01/pdfs/ BOE-A-2010-10421.pdf 
Texto Refundido de la Ley de Sociedades de Capital, relativa a la regulación de la conducta de los administradores en el ámbito de sus funciones societarias.

Al final de estas líneas y a modo de conclusión, cabe señalar que con esta revisión no exhaustiva se han buscado dos cosas: una, sacar a la luz la idea de que la regulación de las actividades corporativas en los mercados bursátiles precisan ser adaptadas a la exigencia de los nuevos hechos de la globalización económica, que debe hacerse en clave de interdisciplinariedad con otras áreas del conocimiento pues se trata de disipar las consecuencias nocivas de un mismo hecho; y dos, mostrar la reacción regulativa global de convenciones, pactos, acuerdos, directrices, decisiones, textos y reglas jurídicas concretas, dado que descansan en el mismo eje de soluciones. Claro está, todo ello con el fin de que las instituciones legitimadas para la adaptación regulativa ajusten a reglas de derecho la realidad del mercado global y disipen, con esta lógica, el impacto nocivo de los vicios de la corrupción corporativa ${ }^{58}$.

Todas las voces en esta línea de solutio han de ser acogidas, partiendo de la base empírica de que los distintos estudios en corrupción arrojan que esta existe en todo el mundo, y no precisamente en niveles mínimos ${ }^{59}$, y ella es, según Luis Pablo Slavin ${ }^{60}$ no la fuente, sino el efecto de un capitalismo depredador ${ }^{61}$ que, vistas

58 Se habla de un triángulo de hierro. Ello por cuanto el sector privado no siempre es víctima en los círculos de corrupción. Este círculo o triángulo de hierro está formado por la clase política, la alta burocracia y las grandes empresas. Con esa lógica actúan, por ejemplo, financiando campañas políticas y curules para el Congreso, como puestos para funcionarios públicos. Dilia Gómez, Corrupción y colusión: asuntos del sector empresarial en Colombia, XVII Revista Prolegómenos, 33, 43-56, 47 (2014). Disponible en: http://www.umng.edu.co/ documents/guest $/ 4 . \% 20$ Programas $\% 20$ academicos/Facultad $\% 20 \mathrm{de} \% 20$ Derecho/Centro $\% 20$ de $\% 20$ investigaciones/3.\%20CORRUPCION $\% 20$ Y\%20COLUSION.pdf. La autora concluye en este interesante trabajo que en una sociedad basada cada vez más en el desarrollo de los mercados debe motivarse a las empresas para hacer frente a la corrupción, paralelo a la pena privativa de la libertad, que es un elemento predominantemente de disuasión, y en el epílogo apunta que más que imposición legal, se trata de fomentar una cultura de legalidad y de ética.

59 Antonio Argandoña, La corrupción y las empresas, 0-10, 1 (IESE Business School, Universidad de Navarra, Occasional Paper OP-07/21, 2007). Disponible en: http://www.iese.edu/research/ pdfs/OP-07-21.pdf

60 Luis Pablo Slavin, El capitalismo depredador. Los escándalos corporativos del siglo XXI, 143 (Editorial Biblos, Buenos Aires, 2005).

61 Luis Pablo Slavin expone los argumentos de ello, partiendo de los mismos fundamentos de quienes lo defienden, de quienes defienden el capitalismo moderno. Así se deduce del título de un artículo El capitalismo no tiene la culpa, publicado en The Economist, que la defensa es por sí misma el reconocimiento de una cruda realidad: cada vez la pobreza se extiende en el mundo. Y en este sentido, saca a la luz también una crónica de los casos de corrupción corporativa más sonados, y no solo ello, sino que se interroga si corresponde o no controlar a 
las cosas tal como están, requiere ponderación en relación con sus ventajas y evitar, en este sentido, márgenes de daño bajo criterios de estabilidad normativa, no de universalidad absoluta ${ }^{62}$. En esta lógica será posible, por ejemplo, disipar el 51\% de fraude financiero que registra Colombia en los últimos tiempos, según la encuesta de fraude de $\mathrm{KPMG}^{63}$, y junto a ello es ineludible también controlar a las corporaciones ${ }^{64}$, a fin de prevenir escándalos corporativos como los de Parmalat, Enron, Auditora Andersen, Nortel Networks, Royal Dutch Shell Group y, entre tantos otros, en nuestro medio los de Ecopetrol e Interbolsa.

De todos ellos corresponde decir que tienen los mismos rasgos de oscuridad corporativa: entrega de tanto en cuanto actos legítimos, como un cactus que expone una flor por día, pero que conserva estables sus espinas.

las corporaciones. Luis Pablo SLAVIn, El capitalismo depredador. Los escándalos corporativos del siglo XXI, 143-144 (Editorial Biblos, Buenos Aires, 2005).

62 John Alberto Tito-AÑamuro, Modernización e integración del derecho contractual latinoamericano. Un análisis del método, 16 (Grupo Editorial Ibáñez, Ediciones Uninorte, BogotáBarranquilla, 2012).

63 KPMG Advisory Services, Forensic Services, Encuesta de fraude en Colombia 2013 (KPMG Advisory Services, Bogotá, 2013). Disponible en: http://www.kpmg.com/CO/es/IssuesAnd Insights/ArticlesPublications/Documents/Encuesta $\% 20 \mathrm{de} \% 20$ Fraude $\% 20$ en $\% 20$ Colombia $\% 202013$.pdf

64 Luis Pablo Slavin, El capitalismo depredador. Los escándalos corporativos del siglo XXI, 25 (Editorial Biblos, Buenos Aires, 2005). 


\section{BIBLIOGRAFÍA}

\section{Libros}

Ariza, Leonel, El reporto (Ediciones Pontificia Universidad Javeriana, Bogotá, 2012).

Consejo Privado de Competitividad, CPC, Informe Nacional de Competitividad 2014-2015: Corrupción (Consejo Privado de Competitividad, CPC, Bogotá, 2014). Disponible en: http://www.compite.com.co/site/informe-nacionalde-competitividad-2014-2015/, http://www.compite.com.co/site/wp-content/ uploads/2014/11/CPC_INC-2014-2015-Corrupcion.pdf

Donadío, Alberto, El cartel de Interbolsa. Crónica de una estafa financiera (Sílaba Editores, Bogotá, 2013).

Hardoon, Deborah \& Heinrich, Finn, Global Corruption Barometer 2013 (Transparency International, Berlin, 2013). Disponible en: http://www.transparency.org/ whatwedo/publication/global_corruption_barometer_2013

Rose-Ackerman, Susan, Corruption. A Study in Political Economy (Academic Press, New York, San Francisco, London, 1978).

Rose-Ackerman, Susan, Corruption and Government. Causes, Consequences, and Reform (Cambridge University Press, Cambridge, 1999).

Slavin, Luis Pablo, El capitalismo depredador. Los escándalos corporativos del siglo XXI (Editorial Biblos, Buenos Aires, 2005).

Stiglitz, Joseph E., Globalization and its Discontents (New York, W.W. Norton \& Company, 2002).

Tito-Añamuro, John Alberto, Modernización e integración del derecho contractual latinoamericano. Un análisis del método (Grupo Editorial Ibáñez, Ediciones Uninorte, Bogotá-Barranquilla, 2012).

\section{Contribución en obras colectivas}

Stiglitz, Joseph E., More Instruments and Broader Goals: Moving Toward the PostWashington Consensus (The 1998 WIDER Annual Lecture, Helsinki, 1998). https://www.globalpolicy.org/component/content/article/209/43245.html

Stiglitz, Joseph E., The Role of Government in the Economies of Developing Countries, en Development Strategy and Management of Market Economy 1 (EDMOND Malinvaud, Jean-Claude Milleron, Mustapha Nabli, Amartya K. Sen, Aruun Sengupta, Nicholas Stern, Joseph E. Stiglitz \& Kotaro Suzumura, eds., Clarendon Press, Oxford, 1997). 


\section{Revistas}

BoEHM, Frédéric, Corrupción y captura en la regulación de los servicios públicos, 7 Revista de Economía Institucional, 13, 245-263 (2005). Disponible en: http://www.cdh. uchile.cl/media/publicaciones/pdf/5/283.pdf

Botero-Bernal, Andrés, La corrupción: tensión entre lo político y lo jurídico, 3 Opinión Jurídica, 6, 37-58 (2004). Disponible en: http://revistas.udem.edu.co/index.php/ opinion/article/view/1314/1295

Carbajo, Fernando, Corrupción en el sector privado (I): la corrupción privada y el derecho privado patrimonial, 10 Iustitia, 281-342 (2012). Disponible en: http:// www.ustabuca.edu.co/gpresenzia/vista/tpl/ustabmanga/revista-iustitia.html

Carrascosa-González, Javier, Sociedades fantasma y derecho internacional privado, 27 Revista Electrónica de Estudios Internacionales, REEI, 1-54 (2014). Disponible en: http://www.reei.org/index.php/revista/num27/articulos/sociedades-fantasmaderecho-internacional-privado

Gómez, Dilia, Corrupción y colusión: asuntos del sector empresarial en Colombia, XVII Revista Prolegómenos, 33, 43-56 (2014). Disponible en: http://www.umng.edu. co/documents/guest/4.\%20Programas $\% 20$ academicos/Facultad $\% 20 \mathrm{de} \% 20$ Derecho/Centro\%20de $\% 20$ investigaciones/3.\%20CORRUPCION $\% 20 Y \% 20$ COLUSION.pdf

González-Espinosa, Ana Carolina \& Boehm, Frédéric, Medir la corrupción: de la generación de conciencia a los peligros de la mala interpretación, 11 Revista Ópera, 259-277 (2013). Disponible en: http://revistas.uexternado.edu.co/index.php/opera/ article/view/3573/3609

Oleas, Sebastián, Corrupción, 51 Koyuntura, 7, 1-7 (2015). Disponible en http://www. usfq.edu.ec/publicaciones/koyuntura/Documents/koyuntura_2015-51.pdf

Rodríguez-Rodríguez, Néstor, El contrato de corresponsalía y su papel en el caso Interbolsa, XVII Revista Prolegómenos, 34, 123-145 (2014). Disponible en: http:// www.redalyc.org/articulo.oa?id $=87633272008$

\section{Working papers}

Argandoña, Antonio, La corrupción y las empresas, 0-10 (IESE Business School, Universidad de Navarra, Occasional Paper OP-07/21, 2007). Disponible en: http://www.iese.edu/research/pdfs/OP-07-21.pdf

Rose-Ackerman, Susan, The Political Economy of Corruption - Causes and Consequences (Public Policy for the Private Sector 74, World Bank, Washington D.C., 1996). Disponible en: http://documents.worldbank.org/curated/en/1996/04/696655/ political-economy-corruption-causes-consequences 


\section{Tratados internacionales}

Organización de Naciones Unidas, Convención de Naciones Unidas contra la Corrupción, Resolución 58/4 de la Asamblea General de Naciones Unidas, 31 de octubre de 2003. Disponible en: http://www.unodc.org/pdf/corruption/ publications_unodc_convention-s.pdf

Organización de Naciones Unidas, Los diez principios del Pacto Global, 2004. Disponible en: http://www.pactomundial.org/, https://www.unglobalcompact. org/

\section{Documentos, informes, reportes}

BRC Investor Services, Revisión anual Interbolsa S. A., Sociedad Comisionista de Bolsa (2004). Disponible en: http://brc.com.co/archivos/RAInterbolsa-Dic04.pdf

KPMG Advisory Services, Forensic Services, Encuesta de fraude en Colombia 2013 (KPMG Advisory Services, Bogotá, 2013). Disponible en: http://www.kpmg. $\mathrm{com} / \mathrm{CO} / \mathrm{es} /$ IssuesAndInsights/ArticlesPublications/Documents/Encuesta $\% 20$ de $\% 20$ Fraude $\% 20$ en $\% 20$ Colombia $\% 202013$.pdf

\section{Normatividad internacional}

España, Ley 12/2010, de 30 de junio, por la que se modifica la Ley 19/1988, de 12 de julio, de Auditoría de Cuentas, la Ley 24/1988, de 28 de julio, del Mercado de Valores y el texto refundido de la Ley de Sociedades Anónimas aprobado por el Real Decreto Legislativo 1564/1989, de 22 de diciembre, para su adaptación a la normativa comunitaria, 159 Boletín Oficial del Estado, BOE, 1 de julio de 2010. Disponible en: http://www.boe.es/boe/dias/2010/07/01/pdfs/BOE-A-2010-10421. pdf

España, Real Decreto Legislativo 1/2010, de 2 de julio, por el que se aprueba el texto refundido de la Ley de Sociedades de Capital, 161 Boletín Oficial del Estado, BOE, 3 de julio de 2010. Disponible en: http://www.boe.es/buscar/act. php?id=BOE-A-2010-10544

Unión Europea, Reglamento CE 1606/2002 del Parlamento Europeo y del Consejo, relativo a la aplicación de normas internacionales de contabilidad, Bruselas, 19 de julio de 2002. Disponible en: http://eur- http://eur-lex.europa.eu/legal-content/ ES/TXT/?uri=celex:32002R1606

\section{Normatividad colombiana}

Decreto 663 de 1993, por medio del cual se actualiza el Estatuto Orgánico del Sistema Financiero y se modifica su titulación y numeración, 40.820 Diario Oficial, 5 de abril de 1993. Disponible en: http://www.secretariasenado.gov.co/senado/ basedoc/estatuto_organico_sistema_financiero.html

Decreto 4432 de 2006, por el cual se dictan disposiciones sobre las operaciones de 
reporto o repo, simultáneas y transferencia temporal de valores, 46.479 Diario Oficial, 11 de diciembre de 2006. Disponible en: http://www.alcaldiabogota.gov. co/sisjur/normas/Norma1.jsp?i=22403\#0

Decreto 2878 de 2013, por el cual se modifica el Decreto 2555 de 2010 en relación con las operaciones de reporto o repo, simultáneas y transferencia temporal de valores y se dictan otras disposiciones. Disponible en: http://wsp.presidencia. gov.co/Normativa/Decretos/2013/Documents/DICIEMBRE/11/DECRETO $\% 20$ 2878\%20DEL\%2011\%20DE\%20DICIEMBRE\%20DE\%202013.pdf

Ley 599 de 2000, por la cual se expide el Código Penal. Disponible en: http://www. alcaldiabogota.gov.co/sisjur/normas/Norma1.jsp?i=6388

Ley 1474 de 2011, por la cual se dictan normas orientadas a fortalecer los mecanismos de prevención, investigación y sanción de actos de corrupción y la efectividad del control de la gestión pública, 48.128 Diario Oficial, 12 de julio de 2011. Disponible en: http://www.secretariasenado.gov.co/senado/basedoc/ley_1474_2011.html

Superintendencia Financiera, Resolución 1795 de 2012, por medio de la cual se adopta la medida de toma posesión inmediata de los bienes, haberes y negocios de la sociedad comisionista de bolsa INTERBOLSA S.A. Disponible en: www. portafolio.co/sites/portafolio.co/files/r1795_12.doc

Superintendencia Financiera, Resolución 1812 de 2012, por la cual se ordena la liquidación forzosa administrativa de la sociedad comisionista de bolsa INTERBOLSA S.A., 7 de noviembre de 2012. Disponible en: http://actualicese. com/normatividad/2012/11/07/resolucion-1812-de-07-11-2012/

\section{Jurisprudencia internacional}

España, caso Banesto, Sentencia 867/2002, del Tribunal Supremo, Segunda Sala Penal, 29 de julio de 2002. Disponible en: http://estaticos.elmundo.es/especiales/2002/07/ economia/conde/1a100.pdf

\section{Medios de comunicación, prensa}

Ariza, Leonel, El contrato de reporto o las famosas operaciones repo, Portafolio (21 de abril de 2014). Disponible en: http://www.portafolio.co/opinion/blogs/elcoloquio-juridico/el-contrato-reporto-o-las-famosas-operaciones-repo-parte-i

Bonilla, María Elvira, ¿ Y la corrupción privada?, El País (2 de mayo de 2013). Disponible en: http://www.elpais.com.co/elpais/opinion/columna/maria-elvira-bonilla/ycorrupcion-privada

Fernández, David, La corrupción es un baile de dos, El País (21 de diciembre de 2014). Disponible en: http://economia.elpais.com/economia/2014/12/18/ actualidad/1418926974_691303.html

Gómez-Martínez, Miguel, Corrupción privada, Portafolio (3 de abril de 2012). Disponible en: http://www.portafolio.co/columnistas/corrupcion-privada

Los 5 momentos de Interbolsa, Revista Dinero (16 de noviembre de 2014). Disponible 
en: http://www.dinero.com/pais/articulo/momentos-mas-importantesinterbolsa/203272

Quevedo, Norbey, Interbolsa: la debacle anunciada. La liquidación de la sociedad, El Espectador (11 de noviembre de 2012). Disponible en: http://www.elespectador. com/noticias/investigacion/interbolsa-debacle-anunciada-articulo-386382

Zuluaga, María Fernanda, Corridori queda libre y jueza defiende decisión. Funcionaria que ordenó libertad del cerebro del descalabro de Interbolsa critica a la Fiscalía, El Tiempo (2 de julio de 2015). 